\title{
Systematic review and meta-analysis: the relationship between the Helicobacter pylori dupA gene and clinical outcomes
}

\author{
Seiji Shiota ${ }^{1,2}$, Osamu Matsunari ${ }^{1,2}$, Masahide Watada ${ }^{1,2}$, Katsuhiro Hanada ${ }^{1}$, Yoshio Yamaoka ${ }^{1,3^{*}}$
}

\begin{abstract}
Background: In 2005, the first disease-specific Helicobacter pylori virulence factor that induced duodenal ulcer and had a suppressive action on gastric cancer has been identified, and was named duodenal ulcer promoting gene (dupA). However, the importance of the dupA gene on clinical outcomes is conflicting in subsequent studies. The aim of this study was to estimate the magnitude of the risk for clinical outcomes associated with dupA gene.

Methods: A meta-analysis of case-control studies which provided raw data on the infection rates with the dupApositive H. pylori detected by polymerase chain reaction was performed.

Results: Seventeen studies with a total of 2,466 patients were identified in the search. Infection with the dupApositive H. pylori increased the risk for duodenal ulcer by 1.41-fold (95\% confidence interval [Cl], 1.12-1.76) overall. Subgroup analysis showed that the summary odds ratio (OR) was $1.57(95 \% \mathrm{Cl}, 1.19-2.06)$ in Asian countries and 1.09 (95\% Cl, 0.73-1.62) in Western countries. There was no association between the presence of the dupA gene and gastric cancer and gastric ulcer. Publication bias did not exist.
\end{abstract}

Conclusion: Our meta-analysis confirmed the importance of the presence of the dupA gene for duodenal ulcer, especially in Asian countries.

\section{Background}

Helicobacter pylori (H. pylori) infection is now accepted as the major cause of chronic gastritis. Several epidemiological studies have shown that $H$. pylori infection is also linked to the severe gastritis-associated diseases, including peptic ulcer and gastric cancer (GC) [1]. In 1994, the International Agency for Research on Cancer categorized $H$. pylori infection as a definite group I carcinogen [2]. The infection remains latent in the majority of infected patients, with only approximately $20 \%$ of infected individuals developing severe diseases. One possible reason for the varying outcomes of $H$. pylori infection relates to differences in the virulence of $H$. pylori strains in addition to host, environmental, and dietary factors.

\footnotetext{
* Correspondence: yyamaoka@bcm.edu

'Department of Environmental and Preventive Medicine, Oita University Faculty of Medicine, 1-1 Idaigaoka, Hasama-machi, Yufu-City, Oita 879-5593, Japan

Full list of author information is available at the end of the article
}

Several H. pylori virulence factors associated with peptic ulcer and GC have been reported, including $\operatorname{cag} A$, $v a c A, b a b A$ and oipA [1,3-6]. Lu et al. [7] described a novel virulence factor, duodenal ulcer promoting gene (dupA), which encompassed both jhp0917 and jhp0918 located in the plasticity region of the $H$. pylori genome. Interestingly, the $\operatorname{dup} A$ gene is homologous to $\operatorname{vir} B 4$, a gene encoding a component protein of the type IV secretion system (TFSS) in Agrobacterium tumefaciens. They reported that infections with $d u p A$-positive strains increased the risk for duodenal ulcer (DU) but were protective against gastric atrophy, intestinal metaplasia and GC in the Japanese, Korean and Columbian subjects. Intriguingly, dupA is the first genetic factor of $H$. pylori to be associated with differential susceptibility to DU and $\mathrm{GC}$, and thus it could be considered as a disease specific virulence marker. The pathogenic mechanism of $d u p A$ appears to involve the induction of interleukin (IL)-8 production in the antrum, leading to antrum-predominant gastritis, a well-recognized characteristic of DU [7]. 
However, the role of $\operatorname{dupA}$ was controversial subsequently since several studies were unable to reproduce the observation in other population including Japan [8-12]. Although Hussein recently reported the systematic review which proved the high prevalence of $d u p A-$ positive $H$. pylori in patients with DU [13], he determined the conclusion based on simple combined data but not meta-analysis (e.g., he did not show the meta-analysis model, heterogeneity, publication bias). In this study, we aimed to examine the relationship between the $d u p A$ gene and clinical outcomes based on the method of meta-analysis.

\section{Methods}

A literature search was performed using the PubMed databases for articles published through August 2010, using the following text words: 1) $\operatorname{dupA}$, and 2) pylori or Helicobacter. We did not include abstract alone or unpublished articles.

\section{Inclusion Criteria}

The following criteria were applied to select fully published case-control studies examining the relationship between the $d u p A$ gene and clinical outcomes (gastritis, gastric ulcer [GU], DU, and GC) in adult population; the presence of $d u p A$ gene was examined by polymerase chain reaction (PCR), or PCR plus dot blot; original articles published in English. Studies were excluded if raw data were not presented. When it appeared that the same subjects were presented in multiple reports, the earliest paper was selected. All potentially relevant articles were reviewed by two investigators (S.S and Y.Y) independently and disagreement was resolved by discussion.

\section{Data Extraction}

Data were extracted from each study by investigators independently and entered into a computerized database. The information retrieved covered countries where the study was performed, characteristics of cases and controls, method for detection of the $d u p A$ gene, number of subjects, the $d u p A$ status according to clinical outcomes. Three studies examined the prevalence of the $\operatorname{dup} A$ gene in several countries $[7,8,11]$, thus these data in each country was entered in separate sheet as an independent study.

\section{Statistical analysis}

Summary odds ratios (ORs) and 95\% confidence intervals (CIs) were calculated from the raw data. The MantelHaenszel method was used to test for statistical heterogeneity. When statistical heterogeneity was noted, the proportion of the total heterogeneity variance was calculated using a fixed-effects model from each study to guide the search for sources of methodologic and clinically important variables. To exclude any possible influence of a single study, we performed a sensitivity analysis to evaluate whether the exclusion of any single study substantial altered the magnitude or statistical result of the summary estimate. Publication bias was assessed by funnel plots and regression test by Egger et al [14]. P value of $<0.05$ was considered as statistically significant in all meta-analyses. All analyses were performed using Comprehensive Meta-analysis software (version 2, Biostat, Englewood, NJ).

\section{Results}

The literature searches generated 17 potentially relevant citations. Of these, six articles were excluded (3 were review articles $[13,15,16]$, one was not case-control study [17], one was in vitro study [18], and one was following study [19]), therefore 11 articles met the inclusion criteria. Three articles included several countries (three in Lu et al, four in Argent et al, and two in Schmidt et al). Although Schmidt et al. examined the $\operatorname{dupA}$ status in five countries [11], data from only two countries was casecontrol. In this study, data from different countries in one article was considered as separate studies (data); therefore, seventeen studies with a total of 2,466 patients met the inclusion criteria (Table 1). Among these studies, there was no age- and sex-matched case-control study. The $d u p A$ status was evaluated by PCR technique except two studies which performed PCR and dot blot technique $[12,20]$. Multiple primer pairs were used in 11 studies [8,10-12,20-22]. The $\operatorname{dupA}$ status in seven studies was determined based on the presence both of jhp0917 and jhp0918 (dupA-positive only if both jhp0917 and jhp0918 were positive) $[7,9,22-24]$.

\section{The association between the $\operatorname{dupA}$ status and duodenal ulcer}

The prevalence of the $\operatorname{dupA}$ gene in DU patients was examined in 17 studies from 13 countries (Figure 1). The prevalence of the $d u p A$ gene ranged from $18.2 \%$ to $92.3 \%$ in DU patients and $6.7 \%$ to $92.4 \%$ in controls. Among 17 studies, significantly higher prevalence of the dupA gene in DU compared with control was found in five studies [7,11,20,21].

The overall prevalence of the $\operatorname{dupA}$ gene was $49.5 \%$ (376 of 759) in DU and 42.5\% (408 of 960) in controls, yielding an estimate OR of 1.33 (95\% CI, 1.09-1.60). Summary OR in fixed-effect model was 1.41 (95\% CI, $1.12-1.76)$. However, the test of heterogeneity was significant among these studies $(\mathrm{Q}=28.15$ with d.f. $=16, \mathrm{p}=$ $0.03)$, suggesting the existence of either methodologic or clinical heterogeneity. By exploring the sources of heterogeneity, we found that the study by Gomes et al. [10] showed the larger differential in the prevalence of the $d u p A$ gene compared with other studies. They reported 
Table 1 List of studies included in the meta-analysis

\begin{tabular}{|c|c|c|c|c|c|c|c|c|c|c|c|c|c|c|}
\hline \multirow[b]{2}{*}{ Authors } & \multirow[b]{2}{*}{ Country } & \multirow[b]{2}{*}{ Reference } & \multicolumn{3}{|c|}{ Gastritis } & \multicolumn{3}{|c|}{ Duodenal ulcer } & \multicolumn{3}{|c|}{ Gastric ulcer } & \multicolumn{3}{|c|}{ Gastric cancer } \\
\hline & & & Positive & all & & positive & all & & positive & all & & positive & all & \\
\hline Lu & Japan & 7 & 7 & 50 & $14.0 \%$ & 11 & 30 & $36.7 \%$ & 13 & 50 & $26.0 \%$ & 3 & 30 & $10.0 \%$ \\
\hline Lu & Korea & 7 & 2 & 30 & $6.7 \%$ & 24 & 65 & $36.9 \%$ & 5 & 30 & $16.7 \%$ & 3 & 50 & $6.0 \%$ \\
\hline Lu & Colombia & 7 & 15 & 40 & $37.5 \%$ & 22 & 45 & $48.9 \%$ & 12 & 30 & $40.0 \%$ & 6 & 50 & $12.0 \%$ \\
\hline Arachchi & India & 20 & 16 & 70 & $22.9 \%$ & 36 & 96 & $37.5 \%$ & & & & & & \\
\hline Argent & South Africa & 8 & 11 & 15 & $73.3 \%$ & 12 & 13 & $92.3 \%$ & & & & 16 & 18 & $88.9 \%$ \\
\hline Argent & Belgium & 8 & 29 & 76 & $38.2 \%$ & 20 & 40 & $50.0 \%$ & & & & 10 & 19 & $52.6 \%$ \\
\hline Argent & USA & 8 & 9 & 20 & $45.0 \%$ & 9 & 21 & $42.9 \%$ & 2 & 3 & $66.7 \%$ & & & \\
\hline Argent & China & 8 & 3 & 12 & $25.0 \%$ & 2 & 11 & $18.2 \%$ & 2 & 5 & $40.0 \%$ & 1 & 1 & $100.0 \%$ \\
\hline Douraghi & Iran & 9 & 34 & 68 & $50.0 \%$ & 15 & 30 & $50.0 \%$ & 9 & 23 & $39.1 \%$ & 20 & 36 & $55.6 \%$ \\
\hline Gomes & Brazil & 10 & 133 & 144 & $92.4 \%$ & 110 & 126 & $87.3 \%$ & & & & 71 & 81 & $87.7 \%$ \\
\hline Hussein & Iraq & 21 & 5 & 29 & $17.2 \%$ & 9 & 15 & $60.0 \%$ & 2 & 5 & $40.0 \%$ & & & \\
\hline Pacheco & Brazil & 23 & 18 & 29 & $62.1 \%$ & 13 & 20 & $65.0 \%$ & 14 & 24 & $58.3 \%$ & & & \\
\hline Zhang & China & 24 & 51 & 133 & $38.3 \%$ & 46 & 101 & $45.5 \%$ & 11 & 47 & $23.4 \%$ & 19 & 79 & $24.1 \%$ \\
\hline Schmidt & Sweden & 11 & 13 & 20 & $65.0 \%$ & 7 & 11 & $63.6 \%$ & & & & 13 & 21 & $61.9 \%$ \\
\hline Schmidt & China & 11 & 15 & 52 & $28.8 \%$ & 10 & 16 & $62.5 \%$ & & & & 12 & 22 & $54.5 \%$ \\
\hline Nguyen & Japan & 12 & 23 & 78 & $29.5 \%$ & 17 & 62 & $27.4 \%$ & 17 & 59 & $28.8 \%$ & 10 & 34 & $29.4 \%$ \\
\hline Yeh & Taiwan & 22 & 24 & 94 & $25.5 \%$ & 13 & 57 & $22.8 \%$ & 6 & 30 & $20.0 \%$ & & & \\
\hline
\end{tabular}

the prevalence of the dupA gene was $87.3 \%$ in DU and $92.4 \%$ in control. In addition, the study by Lu et al. in Korea showed the lower prevalence of the $\operatorname{dup} A$ gene especially in control (6.7\%) [7]. Sensitivity analysis excluding these 2 studies showed a similar OR of 1.46 with a 95\% CI of 1.15-1.85 and the test of heterogeneity was no longer statistically significant $(\mathrm{Q}=18.05$ with $\mathrm{d}$. $\mathrm{f} .=14, \mathrm{p}=0.20)$. Publication bias did not exist (intercept, 1.28; $\mathrm{p}=0.17$ ).

Subgroup analysis was also performed by two areas (Asian or Western countries). The study in South Africa [8] was not included in both. The prevalence of the dupA gene was $37.9 \%$ (183 of 483) in DU and $29.2 \%$ (180 of 616 ) in controls in Asian countries. It was $68.8 \%$ (181 of 263) in DU and $66.0 \%$ (217 of 329) in controls in Western countries. Summary OR was 1.57 (95\% CI,

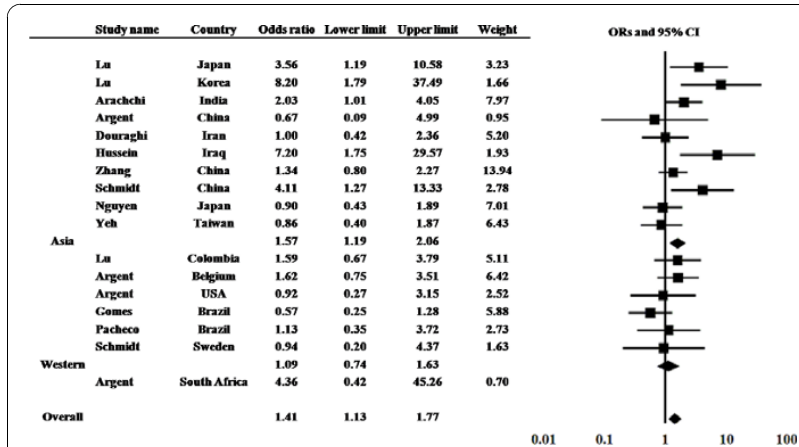

Figure 1 The results of meta-analysis for the risk of duodenal ulcer in dupA-positive $\boldsymbol{H}$. pylori infection. Odds ratios (ORs) and their $95 \%$ confidence intervals $(\mathrm{Cl})$ in summary and for each study are presented with weighting in a fixed-effect model.
1.19-2.06) in Asian countries and 1.09 (95\% CI, 0.73$1.62)$ in Western countries. When the study by Gomes et al. was excluded, it was $51.8 \%$ (71 of 137) in DU and $45.4 \%$ (84 of 185 ) in controls in Western countries $(\mathrm{OR}=1.34$ with a $95 \% \mathrm{CI}, 0.85-2.13)$.

\section{The association between the dupA status and} gastric cancer

The prevalence of the $\operatorname{dup} A$ gene in GC patients was examined from 12 studies from 9 countries (Figure 2). The prevalence ranged from $6.0 \%$ to $100 \%$ in GC patients and $6.7 \%$ to $92.4 \%$ in controls. Among 12 studies, significantly higher prevalence in GC compared with control was found in two studies $[7,11]$.

The overall prevalence of the $d u p A$ gene was $41.7 \%$ (184 of 441) in GC and 46.8\% (336 of 718) in controls, yielding an estimate OR of 0.80 (95\% CI, 0.63-1.02). Summary OR in fixed-effect model was 0.88 (95\% CI, 0.66-1.17). However, significant heterogeneity existed

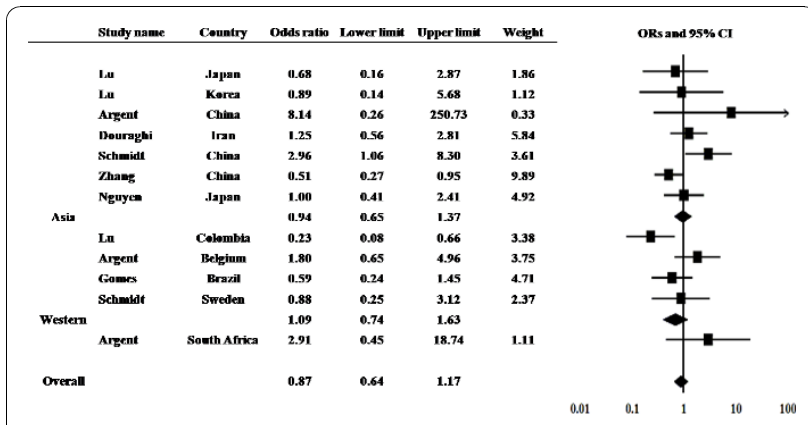

Figure 2 The results of meta-analysis for the risk of gastric cancer in dupA-positive $H$. pylori infection. 
among these studies $(\mathrm{Q}=21.44$ with d.f. $=12, \mathrm{p}=0.04)$. The study in Colombia by Lu et al. [7] showed the larger differential in the prevalence of the $\operatorname{dup} A$ gene when compared with other studies. They reported the prevalence of the dupA gene was $6.0 \%$ in GC and $6.7 \%$ in control. Sensitivity analysis excluding this study showed a similar OR of 0.98 with a $95 \%$ CI of $0.72-1.32$ with no heterogeneity $(\mathrm{Q}=14.73$ with d.f. $=11, \mathrm{p}=0.19)$.

Subgroup analysis also did not show the significant association between GC and dupA both in Asian and Western countries. The prevalence of the $\operatorname{dupA}$ gene was $27.0 \%$ (68 of 252 ) in GC and $31.9 \%$ (135 of 423 ) in controls in Asian countries. The prevalence was 58.5\% (100 of 171) in GC and 67.9\% (190 of 380) in controls in Western countries.

The association between the dupA status and gastric ulcer The prevalence of the $\operatorname{dup} A$ gene in gastric ulcer (GU) patients was examined from 11 studies from 9 countries (Figure 3). The prevalence ranged from 16.7 to $66.7 \%$ in GU patients and 6.7 to $62.1 \%$ in controls. Among 11 studies, no study showed the significantly higher prevalence in GU compared with control.

The overall prevalence of the $d u p A$ gene was $30.3 \%$ (93 of 306) in GU and $32.7 \%$ (191 of 583) in controls, yielding an estimate OR of 0.90 (95\% CI, 0.66-1.20). Summary OR in fixed-effect model was 0.95 (95\% CI, 0.68-1.32) with no heterogeneity $(\mathrm{Q}=10.25$ with d.f. $=10, \mathrm{p}=0.41)$. Subgroup analysis also did not show the significant association between GC and the $\operatorname{dupA}$ status both in Asian and Western countries. The prevalence of the $d u p A$ gene was $26.1 \%$ (65 of 249) in GU and 30.2\% (149 of 494) in controls in Asian countries. The prevalence was 49.1\% (28 of 57 ) in GC and $47.2 \%$ (42 of 89 ) in controls in Western countries.

\section{The difference of prevalence in Asian and}

\section{Western countries}

The overall prevalence of the $d u p A$ gene was $31.0 \%$ (496 of 1,600) in Asian countries and 64.1\% (526 of 820) in Western countries. It was significantly higher in

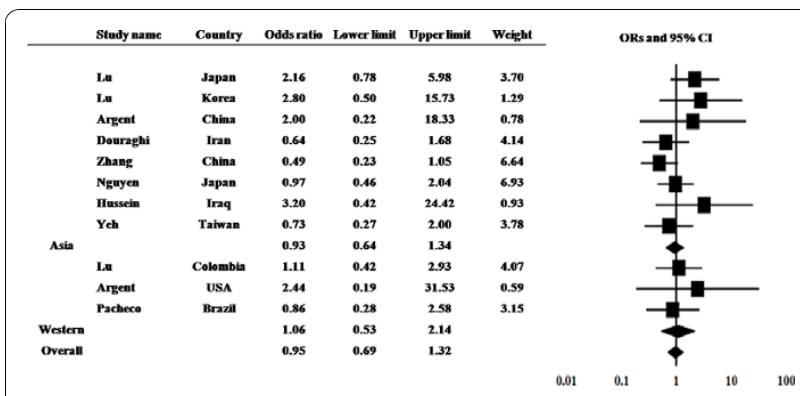

Figure 3 The results of meta-analysis for the risk of gastric ulcer in dupA-positive $H$. pylori infection.
Western countries than Asian countries ( $\mathrm{p}<0.0001$ ). When the study by Gomes et al. was excluded, this trend did not change $(\mathrm{p}<0.0001)$.

\section{Discussion}

Our present meta-analysis shows that the presence of the $d u p A$ gene was significantly associated with DU. Although several studies failed to show the positive association between the $\operatorname{dup} A$ status and clinical outcomes, the meta-analysis confirmed the original report in 2005 [7]. Especially, the presence of the $\operatorname{dup} A$ gene was associated with DU in Asian countries; however it was not in Western countries. This difference may be due to the different prevalence of the $\operatorname{dupA}$ gene between Asian and Western countries. Furthermore, the study by Gomes et $a l$. was the resource of heterogeneity due to larger difference compared with other studies. This mean the simple combined calculation such as the report by Hussein [13] is not strictly accurate to concluded although the trend was not changed. In addition, we found that the several miscount exist in the report by Hussein (e.g., he counted the mean age but not the number of subjects from the study Zhang et al. [24] and mistook the calculation from the study by Pacheco et al. [23]).

When Argent et al. combined Belgian and South African populations, the presence of the $\operatorname{dup} A$ gene was significantly associated with the presence of GC. There was also a non-significant trend towards an association between the $\operatorname{dup} A$ gene and DU in the combined Belgian and South African population. However, we did not include the South Africa in Western countries. It is not relevant to combine random populations since it is unclear whether the South African strains were taken from patients of European descent and recent studies confirmed that the genomic structures of some South African strains (i.e., HpAfrica2 type) were relatively different from those from the European population (i.e., HpEurope type) [25,26].

In a study examining strains from Brazilian children and adults, the prevalence of the $\operatorname{dup} A$ gene was extremely high $(92 \% ; 445 / 482)$ irrespective of clinical outcomes [10]. Interestingly, the frequency of the $d u p A$ gene was significantly higher in strains from children than in those from adults. $H$. pylori infection is typically acquired in childhood and persists throughout life unless treated with a combination of anti-acid and antimicrobial therapy, so it is speculated that the $\operatorname{dupA}$ gene might be lost during long-term infections in which the gastric mucosa gradually develop chronic atrophic gastritis and GC. Therefore, their results might partially support the original hypothesis that the $\operatorname{dup} A$ gene is a marker associated with gastric damage that leads to the development of gastric cancer. Therefore, we need to pay attention to the age of each disease in case-control study. For example, mean age of DU was younger than 
that of gastritis in the study by Zhang et al. (41 years old in DU vs 59 years old in gastritis) [24]. Case-control study matched age- and sex-should be performed in the future.

Overall, there are distinct geographical variations in the prevalence of the $\operatorname{dup} A$ gene, and there appears to be an association between $\operatorname{dup} A$ and DU in some populations but not in others. As Argent et al. [8] reported, the association of $\operatorname{dupA}$ with DU in only some populations could reflect differences in the definition or diagnosis of ulcers or in the use of drugs that either cause or heal ulcers in these populations. In addition, the discrepancy could be related to the limitation of PCR techniques for detecting the intact $d u p A$ gene. In some studies, only one set of primer pairs for $j h p 0917$ and $j h p 0918$ was used $[7,9,23,24]$ : use of multiple primer pairs is recommended for detection of the dupA gene in future studies. None of the previous reports considered the frameshift mutation after position 1385 as a criterion for the presence of the $\operatorname{dupA}$ gene $[7,10]$. More importantly, Gomes et al. reported frameshift mutations in 14/86 (16\%) dupA-positive sequenced samples [10]; a single adenine insertion after position 1426 of $d u p A$ or at position 2998 of the jhp0917-jhp0918 gene of the $J 99$ strain that created a premature stop codon and may have considerable effects on protein expression or function. In their study, they counted the truncated samples as $d u p A$-positive; however, it is clear that these mutated sequences would not produce intact DupA protein. For example, the expression of the blood group antigen binding adhesin (BabA) protein does not always correlated with the $b a b A$ gene expression [27]. It will be better to detect intact $d u p A$ by measuring intact DupA protein using immunoblotting techniques, which has not been reported previously. In addition, the vir genes exist before and after the region of the $d u p A$ locus [16]. In the strain Shi470, for example, $\operatorname{virB2}$, virB3, virB4 (dupA), virB8, virB9, virB10, virB11, $\operatorname{virD4}$, and $\operatorname{vir} D 2$ were detected. These are structurally similar to the type IV secretion system (T4SS) called cag PAI and ComB and thought to be the third T4SS. Recently, T4SS containing $d u p A$ was named as $t f s 3 a$, and T4SS having virB4 sequence, but not $d u p A$ was named as $t f_{S} 3 b$ [28]. These observations suggest that only strains that are intact $d u p A$-positive and form a novel type IV secretion system might be involved in gastroduodenal diseases. If this is true, examining the presence of DupA/ dupA alone might not be sufficient. Study on DupA is still in their early stages, and great progress is expected in the near future.

\section{Conclusions}

Infection with the $d u p A$-positive $H$. pylori increased the risk for DU overall and this evidence was significant in Asian countries. In contrast, the relationship between $d u p A$ and GC and GU was not clear from the meta-analysis. Case-control study matched age- and sex- should be performed in the future.

\section{Financial support}

None.

\section{Acknowledgements}

This report is based on work supported in part by grants from the National Institutes of Health (DK62813) (YY), and grants-in-Aid for Scientific Research from the Ministry of Education, Culture, Sports, Science and Technology (MEXT) of Japan (22390085 and 22659087)(YY).

\section{Author details}

'Department of Environmental and Preventive Medicine, Oita University Faculty of Medicine, 1-1 Idaigaoka, Hasama-machi, Yufu-City, Oita 879-5593, Japan. ${ }^{2}$ Department of General Medicine, Oita University Faculty of Medicine, 1-1 Idaigaoka, Hasama-machi, Yufu-City, Oita 879-5593, Japan. ${ }^{3}$ Department of Medicine-Gastroenterology, Baylor College of Medicine and Michael E. DeBakey Veterans Affairs Medical Center, 2002 Holcombe Blvd. Houston, Texas 77030 USA.

\section{Authors' contributions}

SS and YY designed the study, reviews potentially relevant articles, and performed the statistical analysis and wrote the manuscript. OM and MW helped to collect and interpret relevant articles and making figures. $\mathrm{KH}$ participated in the design of the study and helped to draft the manuscript. All authors read the final version of the manuscript.

\section{Competing interests}

The authors declare that they have no competing interests.

Received: 12 September 2010 Accepted: 31 October 2010 Published: 31 October 2010

\section{References}

1. Suerbaum S, Michetti P: Helicobacter pylori infection. N Engl J Med 2002, 347:1175-1186.

2. Schistosomes, liver flukes and Helicobacter pylori. IARC Working Group on the Evaluation of Carcinogenic Risks to Humans. Lyon, 7-14 June 1994. IARC Monogr Eval Carcinog Risks Hum 1994, 61:1-241.

3. Atherton J, Cao P, Peek RJ, Tummuru M, Blaser M, Cover T: Mosaicism in vacuolating cytotoxin alleles of Helicobacter pylori. Association of specific vacA types with cytotoxin production and peptic ulceration. J Biol Chem 1995, 270:17771-17777.

4. Basso D, Zambon C, Letley D, Stranges A, Marchet A, Rhead J, Schiavon S, Guariso G, Ceroti M, Nitti D, et al: Clinical relevance of Helicobacter pylori cagA and vacA gene polymorphisms. Gastroenterology 2008, 135:91-99.

5. Gerhard M, Lehn N, Neumayer N, Borén T, Rad R, Schepp W, Miehlke S, Classen M, Prinz C: Clinical relevance of the Helicobacter pylori gene for blood-group antigen-binding adhesin. Proc Natl Acad Sci USA 1999, 96:12778-12783.

6. Yamaoka Y, Kikuchi S, el-Zimaity H, Gutierrez O, Osato M, Graham D: Importance of Helicobacter pylori oipA in clinical presentation, gastric inflammation, and mucosal interleukin 8 production. Gastroenterology 2002, 123:414-424

7. Lu H, Hsu P, Graham D, Yamaoka Y: Duodenal ulcer promoting gene of Helicobacter pylori. Gastroenterology 2005, 128:833-848.

8. Argent R, Burette A, Miendje Deyi $\mathrm{V}$, Atherton J: The presence of dupA in Helicobacter pylori is not significantly associated with duodenal ulceration in Belgium, South Africa, China, or North America. Clin Infect Dis 2007, 45:1204-1206.

9. Douraghi M, Mohammadi M, Oghalaie A, Abdirad A, Mohagheghi M, Hosseini M, Zeraati $\mathrm{H}$, Ghasemi A, Esmaieli M, Mohajerani N: dupA as a risk determinant in Helicobacter pylori infection. J Med Microbiol 2008, 57:554-562.

10. Gomes L, Rocha G, Rocha A, Soares T, Oliveira C, Bittencourt P, Queiroz D: Lack of association between Helicobacter pylori infection with dupA- 
positive strains and gastroduodenal diseases in Brazilian patients. Int J Med Microbiol 2008, 298:223-230.

11. Schmidt H, Andres S, Kaakoush N, Engstrand L, Eriksson L, Goh K, Fock K, Hilmi I, Dhamodaran S, Forman D, Mitchell H: The prevalence of the duodenal ulcer promoting gene (dupA) in Helicobacter pylori isolates varies by ethnic group and is not universally associated with disease development: a case-control study. Gut Pathog 2009, 1:5.

12. Nguyen L, Uchida T, Tsukamoto Y, Kuroda A, Okimoto T, Kodama M, Murakami K, Fujioka T, Moriyama M: Helicobacter pylori dupA gene is not associated with clinical outcomes in the Japanese population. Clin Microbiol Infect 2010, 16:1264-1269.

13. Hussein $\mathrm{N}$ : The association of $\operatorname{dupA}$ and Helicobacter pylori-related gastroduodenal diseases. Eur J Clin Microbiol Infect Dis 2010, 29:817-821.

14. Egger M, Davey Smith G, Schneider M, Minder C: Bias in meta-analysis detected by a simple, graphical test. BMJ 1997, 315:629-634.

15. Matysiak-Budnik T, Laszewicz W, Lamarque D, Chaussade S: Helicobacter pylori and non-malignant diseases. Helicobacter 2006, 11(Suppl 1):27-31.

16. Yamaoka Y: Roles of the plasticity regions of Helicobacter pylori in gastroduodenal pathogenesis. J Med Microbiol 2008, 57:545-553.

17. Matteo M, Armitano R, Granados G, Wonaga A, Sánches C, Olmos M, Catalano M: Helicobacter pylori oipA, vacA and dupA genetic diversity in individual hosts. J Med Microbiol 2010, 59:89-95.

18. Hussein N, Argent R, Marx C, Patel S, Robinson K, Atherton J: Helicobacter pylori dupA is polymorphic, and its active form induces proinflammatory cytokine secretion by mononuclear cells. J Infect Dis 2010, 202:261-269.

19. Schmidt H, Andres S, Nilsson C, Kovach Z, Kaakoush N, Engstrand L, Goh K, Fock K, Forman D, Mitchell $\mathrm{H}$ : The cag PAl is intact and functional but HP0521 varies significantly in Helicobacter pylori isolates from Malaysia and Singapore. Eur J Clin Microbiol Infect Dis 2010, 29:439-451.

20. Arachchi H, Kalra V, Lal B, Bhatia V, Baba C, Chakravarthy S, Rohatgi S, Sarma P, Mishra V, Das B, Ahuja V: Prevalence of duodenal ulcerpromoting gene (dupA) of Helicobacter pylori in patients with duodenal ulcer in North Indian population. Helicobacter 2007, 12:591-597.

21. Hussein N, Mohammadi M, Talebkhan Y, Doraghi M, Letley D, Muhammad M, Argent R, Atherton J: Differences in virulence markers between Helicobacter pylori strains from Iraq and those from Iran: potential importance of regional differences in $\mathrm{H}$. pylori-associated disease. J Clin Microbiol 2008, 46:1774-1779.

22. Yeh Y, Cheng H, Chang W, Yang H, Sheu B: Matrix metalloproteinase-3 promoter polymorphisms but not dupA-H. pylori correlate to duodenal ulcers in H. pylori-infected females. BMC Microbiol 2010, 10:218.

23. Pacheco A, Proença-Módena J, Sales A, Fukuhara Y, da Silveira W, PimentaMódena J, de Oliveira R, Brocchi M: Involvement of the Helicobacter pylori plasticity region and cag pathogenicity island genes in the development of gastroduodenal diseases. Eur I Clin Microbiol Infect Dis 2008, 27:1053-1059.

24. Zhang Z, Zheng Q, Chen X, Xiao S, Liu W, Lu H: The Helicobacter pylori duodenal ulcer promoting gene, dupA in China. BMC Gastroenterol 2008, 8:49.

25. Falush D, Wirth T, Linz B, Pritchard J, Stephens M, Kidd M, Blaser M, Graham D, Vacher S, Perez-Perez G, et al: Traces of human migrations in Helicobacter pylori populations. Science 2003, 299:1582-1585.

26. Linz B, Balloux F, Moodley Y, Manica A, Liu H, Roumagnac P, Falush D, Stamer $C$, Prugnolle $F$, van der Merwe $S$, et al: An African origin for the intimate association between humans and Helicobacter pylori. Nature 2007, 445:915-918

27. Yamaoka Y: Roles of Helicobacter pylori BabA in gastroduodenal pathogenesis. World I Gastroenterol 2008, 14:4265-4272.

28. Kersulyte D, Lee W, Subramaniam D, Anant S, Herrera P, Cabrera L, Balqui J, Barabas O, Kalia A, Gilman R, Berg D: Helicobacter Pylori's plasticity zones are novel transposable elements. PLoS One 2009, 4:e6859.

doi:10.1186/1757-4749-2-13

Cite this article as: Shiota et al: Systematic review and meta-analysis: the relationship between the Helicobacter pylori dupA gene and clinical outcomes. Gut Pathogens 2010 2:13.

\section{Submit your next manuscript to BioMed Central and take full advantage of:}

- Convenient online submission

- Thorough peer review

- No space constraints or color figure charges

- Immediate publication on acceptance

- Inclusion in PubMed, CAS, Scopus and Google Scholar

- Research which is freely available for redistribution

Submit your manuscript at www.biomedcentral.com/submit
Ciomed Central 